\title{
Situación actual de la infección vertical por VIH
}

\author{
Current status of vertical HIV infection \\ Javier Ordoñez Ortega* \\ * Servicio de Infectología pediátrica. Instituto Nacional de Pediatría. Centro Médico Nacional "20 de Noviembre" ISSSTE.
}

Al día de hoy, la infección por el virus de inmunodeficiencia humana $(\mathrm{VIH})$ continúa siendo un problema de salud pública. En 2018, la Organización de las Naciones Unidas (ONU) en su Programa Conjunto de las Naciones Unidas sobre el VIH/SIDA (ONUSIDA) reportó que 37.9 millones de personas viven con $\mathrm{VIH} / \mathrm{SIDA}$ a nivel mundial (36.2 millones de adultos; 18.8 millones de mujeres menores a 15 años y 1.7 millones de niños).

Si bien, las defunciones de los pacientes con $\mathrm{VIH} /$ SIDA han disminuido $33 \%$ de un pico de 1.7 millones de decesos en 2004 a 770 mil defunciones en 2018, ${ }^{1}$ a pesar de los grandes esfuerzos preventivos que realiza la Organización Mundial de la Salud (OMS) y la ONUSIDA, anualmente, se presentan 1.7 millones de casos nuevos a nivel mundial.

En el transcurso de los años, la infección, con excepción del continente africano, se concentra más de la mitad de los casos nuevos principalmente en poblaciones clave (trabajadores sexuales, consumidores de drogas, hombres que tienen sexo con hombres, personas transgénero, prisioneros y sus respectivas parejas sexuales).

En el ámbito mundial, de 2010 a 2018, las infecciones en las mujeres entre 15 y 24 años han disminuido en 25\%; sin embargo, al día de hoy, seis mil niñas, adolescentes y adultas jóvenes se infectan por VIH cada semana. ${ }^{1}$ Esto ha suscitado por parte de los gobiernos locales, OMS y ONUSIDA hechos que busquen asegurar el tratamiento antirre-

Financiamiento: Ninguno.

Conflicto de intereses: Ninguno.

https://dx.doi.org/10.35366/94415

Rev Latin Infect Pediatr 2020; 33 (2): 63-65

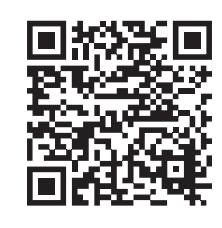

troviral (ARV) en las mujeres embarazadas. Así, en el último reporte de dicha organización, se estimó que $76 \%$ de las mujeres gestantes portadoras de VIH tiene acceso al tratamiento antirretroviral. ${ }^{1}$ Previo a la introducción de este tratamiento en las embarazadas y la profilaxis en los recién nacidos, entre 15 y $45 \%$ de los infantes adquiriría la infección ya sea durante el embarazo, parto o la lactancia materna. ${ }^{1,3}$

La terapia ARV en las mujeres embarazadas y en sus bebés se implementó por primera vez en el protocolo ACTG-076, el cual se llevó a cabo entre 1991 y 1993. Este protocolo consistió en administrar $100 \mathrm{mg}$ de zidovudina vía oral (AZT) antes del parto, cinco veces al día; durante el parto, $2 \mathrm{mg} / \mathrm{kg}$ intravenoso por una hora, y posteriormente una infusión a $1 \mathrm{mg} /$ kg hasta el alumbramiento; para el recién nacido, se administró $2 \mathrm{mg} / \mathrm{kg}$ de AZT cada seis horas durante seis semanas. Con esto, se obtuvo una reducción de 35 a $8.3 \%$ de contagios. . $^{3,4,6}$

Con el advenimiento de nuevas terapéuticas, actualmente, es posible que la mujer llegue al momento del alumbramiento con cargas virales indetectables; además, se ha fortalecido y mejorado el esquema profiláctico de los recién nacidos, aunado a la realización de cesárea en la madre. Con estas acciones, hemos logrado alcanzar tasas de trasmisión vertical de 1 a $2 \% .^{1,3,4}$ Con el mismo enfoque de tratamiento a las mujeres embarazadas, de 2010 a 2017, se han logrado disminuir en al menos $50 \%$ las infecciones por VIH en los infantes, lo que corresponde a 1.4 millones de nuevas infecciones prevenidas.

En América Latina, se presenta un promedio de 100 mil casos nuevos al año (de 79 mil a 130 mil casos) de infección por VIH en la población general. Los países que registran más casos nuevos son: 
Rev Latin Infect Pediatr 2020; 33 (2): 63-65

Brasil (21\%), Costa Rica (21\%), Bolivia (22\%) y Chile (34\%). Regionalmente, la cobertura de tratamiento en las mujeres embarazadas es de $76 \%$ (61-95\%), y la tasa de trasmisión vertical es de 14\% (12-17\%). ${ }^{1}$ En el caso particular de México, al término del año 2018, se notificaron 16,755 casos nuevos de infección por VIH en la población general, donde la mayoría de los casos los observamos en poblaciones clave. Las mujeres representan $17.9 \%$ del total de infectados, empero, con los esfuerzos de las instituciones de salud que buscan asegurar el tratamiento de las mujeres embarazadas, hemos logrado una disminución importante de la trasmisión vertical, con menos de 50 casos reportados en 2018 a nivel nacional y con una reducción cercana a $60 \%$ de los casos verticales en los últimos 10 años. ${ }^{2}$

A pesar de estos resultados alentadores, no debemos confiarnos y, por el contrario, es necesario continuar con la vigilancia epidemiológica de las embarazadas: tomarles una prueba de VIH al momento de su primera consulta y repetir una segunda prueba durante el tercer trimestre. Esta maniobra nos permite captar un mayor número de casos de mujeres embarazadas y la oportunidad de realizar una intervención para prevenir el contagio vertical. ${ }^{5}$

En caso de presentar alguna paciente positiva, el tratamiento antirretroviral está indicado en todas las mujeres gestantes, independientemente del conteo de linfocitos T CD4, CD8 y la carga viral que presenten. Uno de los esquemas de inicio más recomendados es el uso de tenofovir/emtricitabina más raltegravir. ${ }^{5}$

En cuanto a las mujeres seropositivas embarazadas que ya se encontraban recibiendo tratamiento, se debe dar continuidad al esquema ya administrado. Asimismo, se recomienda realizar un recuento de subpoblación de linfocitos T CD4, CD8 y carga viral una vez por trimestre.

En el momento de alumbramiento, si nuestra paciente presenta ruptura prematura de membranas, carga viral $>50$ copias $/ \mathrm{mL}$ o carga viral desconocida, se debe iniciar profilaxis intraparto con zidovudina en infusión intravenosa, la cual debe administrarse cuatro horas antes de la resolución del embarazo: $2 \mathrm{mg} / \mathrm{kg}$ de AZT durante la primera hora y continuar con infusión a $1 \mathrm{mg} / \mathrm{kg}$ para cada hora hasta el nacimiento. ${ }^{5}$

En cuanto al lactante, deberá iniciarse profilaxis en las primeras 12 horas de vida hasta un periodo máximo de 72 horas; el esquema profiláctico debe ajustarse a la edad gestacional y a los factores de riesgo de trasmisión. Cuando el recién nacido es de bajo riesgo, se debe administrar zidovudina (AZT) por cuatro semanas. En caso de alto riesgo, amerita el uso de triple esquema con zidovudina (AZT) más lamivudina (3TC) durante cuatro semanas y nevirapina (NVP) durante dos semanas. ${ }^{5}$

La monitorización del recién nacido se debe realizar a través de la prueba de reacción en cadena de la polimerasa (PCR), la cual se debe obtener en sangre lo más cercano al nacimiento (no del cordón umbilical). En caso de que no se haya realizado y recibió profilaxis, se debe realizar dos semanas después de la suspensión de los antirretrovirales. Además, es necesario repetir una nueva PCR entre los cuatro y seis meses de vida y, si ésta es negativa, se realiza un ELISA-VIH a los 18 meses de edad. Si el ELISA da resultado negativo, se descarta por completo la posibilidad de infección vertical del infante. . $^{5,8}$

El objetivo de la ONUSIDA para 2020 es reducir la trasmisión en la población pediátrica a menos de 20 mil casos anuales a nivel mundial. Este objetivo aún se encuentra distante, pues para 2018 se reportaron 160 mil casos nuevos en menores de 15 años. ${ }^{1,8}$ Sin embargo, es necesario seguir trabajando, pues a pesar de que se han realizado grandes avances para evitar la trasmisión vertical desde su implementación en 1994, nuestra obligación es continuar con este gran esfuerzo, para así lograr nuestra primera generación libre de la infección vertical por VIH.

\section{REFERENCIAS}

1. ONUSIDA. UNAIDS Joint United Nations Programme on HIV/AIDS [artículo en Internet]. Disponible en: https://www. unaids.org/sites/default/files/media_asset/2019-UNAIDSdata_en.pdf

2. DGE-CENSIDA. Registro Nacional de Casos de SIDA [actualización al cierre de 2019]. México, CENSIDA. Disponible en: https://www.gob.mx/censida/documentos/ epidemiologia-registro-nacional-de-casos-de-sida

3. Noguera JA, De José MI. Recomendaciones de la Sociedad Española de Infectología Pediátrica para el seguimiento del niño expuesto al virus de la inmunodeficiencia humana y a fármacos antirretrovirales durante el embarazo y el periodo neonatal. An Pediatría. 2012; 76 (6): 360.e1-360.e9.

4. Moreno PD, García MF, Vázquez LR, Jurado OA. Infección perinatal por VIH-1 no esperada. An Pediatría. 2005; 62 (6): 598-599.

5. Secretaría de Salud, Consejo Nacional para la Prevención y Control del VIH/SIDA. Guía de manejo antirretroviral de las personas que viven con el VIH/SIDA. 9a ed. Ciudad de México: Secretaría de Salud; 2019. 
Rev Latin Infect Pediatr 2020; 33 (2): 63-65

6. Connor EM, Sperling RS, Gelber R, Kiselev P, Scott G, O'Sullivan MJ et al. Reduction of maternal-infant transmission of human immunodeficiency virus type 1 with zidovudine treatment. N Engl J Med. 1994; 331 (18): 1173-1180.

7. González TMI, Antoni NJ. Extracto del "Control y diagnóstico del niño expuesto al VIH del documento de consenso para el seguimiento de la infección por el $\mathrm{VIH}$ en relación con la reproducción, embarazo, parto y profilaxis de la transmisión vertical del niño expuesto". Rev Latin Infect Pediatr. 2018; 31 (4): 131-139.
8. Taylor M, Newman L, Ishikawa N, Laverty M, Hayashi C, Ghidinelli $\mathrm{M}$ et al. Elimination of mother-to-child transmission of HIV and syphilis (EMTCT): process, progress, and program integration. PLOS Med. 2017; 14 (6): e1002329.

$$
\begin{aligned}
& \text { Correspondencia: } \\
& \text { Dr. Javier Ordoñez Ortega } \\
& \text { E-mail: malookim83@gmail.com }
\end{aligned}
$$

